\title{
GREENBOX Horticulture, an Alternative Avenue of Urban Food Production
}

\author{
Ankit Kumar Singh, Xiusheng Yang \\ Department of Natural Resources and the Environment, University of Connecticut, Storrs, CT, USA \\ Email: ankit.singh@uconn.edu, xiusheng.yang@uconn.edu
}

How to cite this paper: Singh, A.K. and Yang, X. (2021) GREENBOX Horticulture, an Alternative Avenue of Urban Food Production. Agricultural Sciences, 12, 1473-1489. https://doi.org/10.4236/as.2021.1212094

Received: November 10, 2021 Accepted: December 18, 2021 Published: December 21, 2021

Copyright $\odot 2021$ by author(s) and Scientific Research Publishing Inc. This work is licensed under the Creative Commons Attribution International License (CC BY 4.0).

http://creativecommons.org/licenses/by/4.0/ (c) (i) Open Access

\begin{abstract}
In response to the pressure on food security caused by rising global population and urbanization, the Yang Laboratory at the University of Connecticut has developed the so-called GREENBOX technology that allows crop growth in individual climate-controlled boxes in urban warehouse environments and other enclosed structures. A GREENBOX unit is a thermally insulated modular structure with LED artificial lighting, soilless (hydroponic) cultivation platform, and complete environmental controls. Multiple GREENBOX units can be integrated into a large production system at various scales. This study evaluated the applicability of the GREENBOX technology in the urban warehouse environment by studying the environmental parameters and productivity. We carried greenhouse growth simultaneously for reference. We grew Butterhead Rex lettuce (Lactuca sativa) over 30-day growing cycles in summer (July-August, 2020) and winter (December, 2020-January, 2021) in an experimental greenhouse and two protocol GREENBOX units located in the high ceiling headhouse of the experimental greenhouse at Storrs, Connecticut. We collected environmental data, including light, temperature, and relative humidity and crop growth data, including wet and dry biomass in the two production systems. Descriptive statistics were used to describe the environmental and biomass data. Results indicated that the GREENBOX could provide desired environmental conditions to sustain crop growth over summer and winter. The Daily Light Integral, controllable at the grower's discretion, in the GREENBOX, ranged between $32.48-36.70 \mathrm{~mol} / \mathrm{m}^{2} \cdot \mathrm{d}$ at crop canopy height. The mean daily temperature and relative humidity in the GREENBOX fell within the optimal ranges of $17^{\circ} \mathrm{C}-29^{\circ} \mathrm{C}$ and $40 \%-60 \%$, respectively. Regardless of seasons, lettuce crops were all healthy and grew to full size over the 30-day cycle. Measured productivity followed similar patterns, similar across both growing locations but higher over summer than winter for both systems. Our study indicated that the GREENBOX technology has a high potential in urban horticulture because it does not require ara-
\end{abstract}


ble land like greenhouses and can utilize existing urban structures for sustainable food production.

\section{Keywords}

GREENBOX, Hydroponics, Lettuce, Sustainable Technologies, Urban Agriculture

\section{Introduction}

Conventional soil-based agriculture has been resource-intensive. According to the United Nations, 70\% of global water use is consumed by agriculture [1]. Moreover, the global population is predicted to increase (2.5 billion in 1950) to a projected 11.2 billion nearing 2100 [2]. The increasing population represents a requirement for an increase in food production capacity in the face of declining arable land per capita [3]. However, the increasing trends of world populations trends are not evenly spread and tend to be concentrated in urban areas. According to the United Nations, more than half the world's citizens live in urban areas, which is projected to be more than $60 \%$ by 2030 [4]. Therefore, relying solely on conventional soil-based agriculture poses stresses to food security. There are many critical issues related to conventional agriculture: water, air, and soil pollution, soil salinization, desertification, climate change-induced droughts, extreme variation in temperatures, extreme variation in solar radiation, and pests [5]. With more frequent and extreme weather patterns, climate change will continue to increase pressures on world agricultural productivity [6]. By FAO estimates, around $33 \%$ of global farmland is degraded to some extent, if not higher [7]. The decrease in productivity of arable land in the face of increasing demand for food is another challenge confronting food production [4]. Another concurrent problem in industrialized countries is the common phenomenon of food retailers underserving socioeconomically disadvantaged areas [8]. These areas are identified as food deserts, defined as urban areas with lower accessibility to fresh foods [9]. Lower income, lower education, and lower health levels are the commonly occurring characteristics of food deserts. Neighborhoods in the vicinity of food deserts tend to have higher adverse health outcomes, mortality, and morbidity [10] [11]. Socioeconomically disadvantaged families tend to have children that are more than likely to develop obesity and diabetes, which together account for $\$ 395$ billion in medical costs and lost productivity annually [12] [13]. As of $2018,11 \%$ of the population in the US faced food insecurity [14]. There is a need to make nutritious food sources readily available to residents of such areas.

Agricultural growth in controlled environments is increasingly used to increase crop productivity and make produce accessible without traveling long food miles. These setups can be referred to as a controlled environment with artificial lighting (CEAL) [15] or plant factories with artificial lighting (PFAL) 
[16], among many others. Controlled Environment Agriculture (CEA) can refer to urban farms that use soilless systems such as hydroponics, aeroponics, or aquaponics [17]. CEAL/PFAL setups can serve as an excellent solution for feeding future cities [18]. Plant factories serve as closed plant production systems with lower interaction with the outside environment [19]. Agriculture needs to focus on reducing natural resource losses, decreasing environmental pollution, and increasing crop returns using innovative technologies [20]. In addition, the agricultural industry needs to increase its productivity to meet market commitments of high-quality produce [21].

The Yang laboratory at the University of Connecticut first introduced the concept of GREENBOX farming as a new system for urban agriculture [22]. The concept presented an overall idea of growing food crops in standard grow boxes in urban structures, with optimal environmental controls that have been greatly improved with the advancement in LED lighting, environmental sensors, and information technology. The GREENBOX technology was specifically designed to be used in urban warehouse conditions (commonly found in urban areas), generally defined with a lower degree of environmental controls, high ceilings, and minimal lighting conditions. Urban warehouse spaces have the distinct advantage of minimal requirements of retrofitting or modification to be ready for GREENBOX crop production. Growing food crops in such settings can effectively use urban spaces, produce different species to be harvested at different times, reduce food transport distances, harvest produce just before they are purchased/consumed, and quickly adopt the new industrial technologies (like robots) to reduce operational costs. Research has been conducted to analyze the energy and water use of the GREENBOX system using dynamic simulation models for lettuce crop production [23], in comparison with conventional greenhouses. The simulation study indicated that the GREENBOX used less water than greenhouses over both summer and winter seasons, and the energy use efficiency of the GREENBOX was lower in the summer and higher in the winter compared to a greenhouse. Since 2019, The Yang Laboratory has initiated a systematic experimental study on the technical and financial feasibilities of the GREENBOX technology. The overall objective of this paper was to demonstrate the GREENBOX as a sustainable and alternative avenue for vegetable crop production in urban settings. We studied the growing environments and productivity of lettuce growth in two protocol GREENBOX units and carried out a parallel growth cycle in an experimental greenhouse for reference and comparison. Using descriptive statistics, we aimed to present the observations on the environmental and biomass patterns in lettuce crop output. We also intend to discuss the overall implications of GREENBOX technology in urban horticulture.

\section{Materials and Methods}

\subsection{Location}

We carried out the experiments in the headspace of the greenhouse (GREENBOX) 

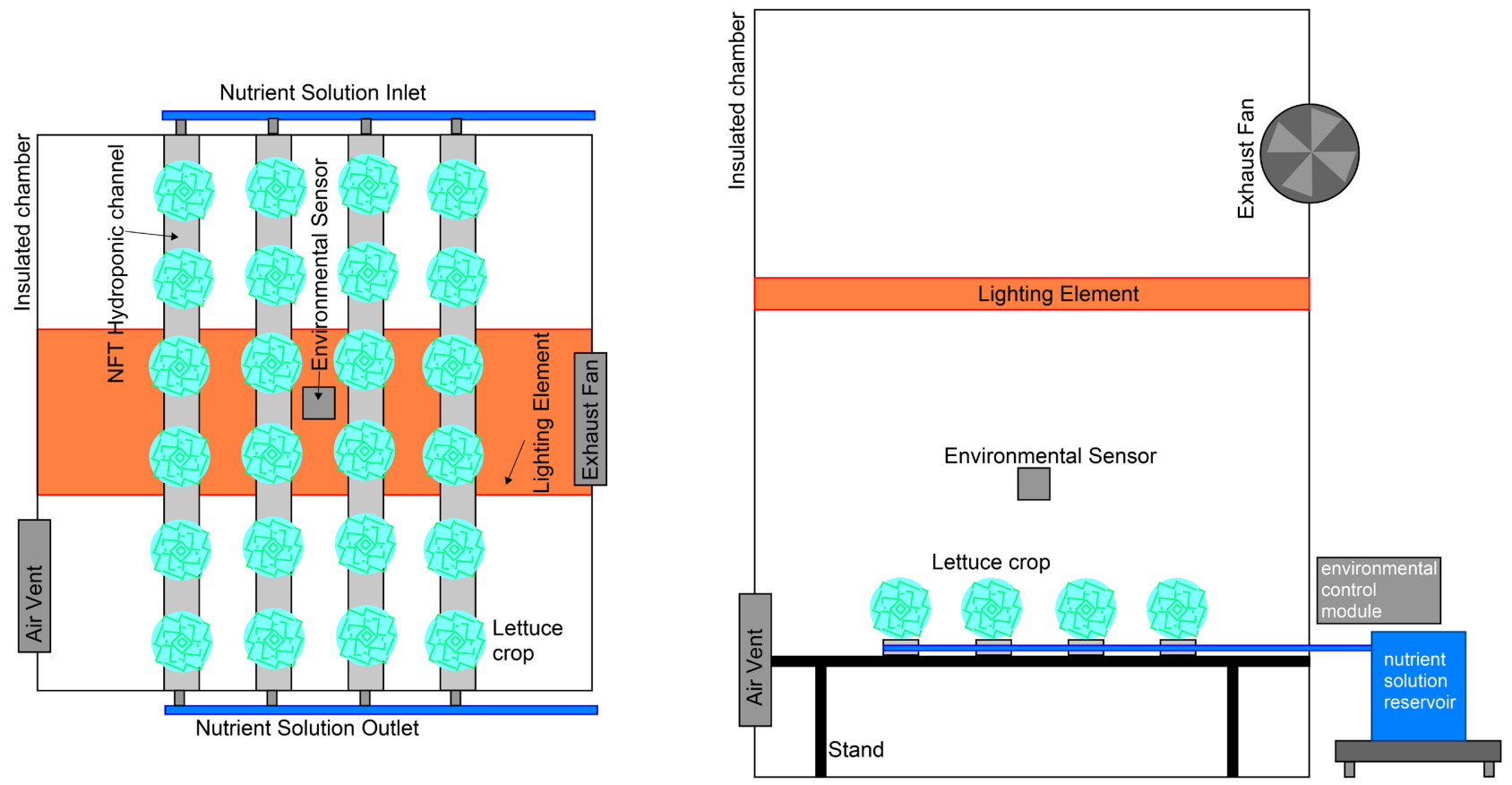

Figure 1. Illustrations of the experimental setup of a GREENBOX unit. The right diagram shows the cross sectional structure of the box seeing from the front, and the left one is a view from the above on the horizontal layout. The two units had exactly the same design. 
The grow tents (The Original Gorilla Grow Tent ${ }^{\circledR} 5 \times 5$, Gorilla Inc., Santa Rosa, California) with dimensions of $1.5 \times 1.5 \times 2.1 \mathrm{~m}$ consisted of an exterior canvas covering (1680D material) were meant to serve as the exterior of the prototype GREENBOX. The interior of these grow tents is comprised of diamond reflective walls to serve as insulation. An LED light source (powerPAR PPLF44, Hydrofarm LLC, Petaluma, California) was installed in each GREENBOX to facilitate photosynthesis. The lighting elements were four feet long, provided white light of 40,000 K color temperature, and had a rated diode life of 50,000 hours. The lighting element was positioned one meter above the plant canopy. Modulating the use of fans (Hyper Fan GL56701400, Hawthorne Gardening Company, Vancouver, Washington) and vents maintained the ambient growing conditions inside the GREENBOX by a forced ventilation system.

Greenhouse Bay 8 is equipped with 1000-watt metal halide HID bulbs, and Bay 6 is equipped with Infinity LED Linear Fixtures (Model number TL-TBAR40K-4FT-58W-V1, Thrive Agritech, New York, New York) in the form of overhead lighting for light control placed one meter above the crop canopy. Greenhouse Bays 8 and 6 are heated by hot water in fin tubes (two loops controlled separately; baseboard and gutter). Passive ridge vents or three exhaust fans (combined with intake louvers) are used for cooling. Both bays are controlled by the Argus Titan greenhouse control system (Surrey, British Columbia, Canada).

The controlled environmental parameters included light intensity, light duration, air temperature, and air moisture content. We used environmental controllers (iPonic 614, Link4 Corp., Burbank, California) to monitor the environment outside the GREENBOX units and inside the greenhouse. The other environmental controller (iPonic 624, Link4 Corp., Burbank, California) was used to monitor and regulate the inside environment conditions in the GREENBOX. The sensors were positioned $0.15 \mathrm{~m}$ above the plant canopy in the GREENBOX and greenhouse.

For growing crops in the GREENBOX and greenhouse, we use hydroponics as means of soilless cultivation. Compared to conventional soil-based growth, hydroponic growth isolates the plant from the soil, thereby preventing exposure to disease, salinity, and drainage issues, along with a rapid turnaround time on crops [25]. The hydroponic nutrient film technique (NFT) channels were placed on a $0.91 \times 0.91 \mathrm{~m}$ tray stand (model number 706121, Fast Fit Ltd., Hawthorne Gardening Company, Vancouver, Washington). The NFT channels (made with UV stabilized plastics) were $0.10 \times 0.05 \times 1.2 \mathrm{~m}$ with holes for plants, spaced for inserting transplants $15.24 \mathrm{~cm}$ apart. We placed the NFT channels $7.62 \mathrm{~cm}$ apart to keep a distance of $15.24 \mathrm{~cm}$ between plants, forming a $4 \times 6$ matrix in each GREENBOX and two panels of $4 \times 6$ in the greenhouse bays. We monitored the $\mathrm{pH}$ and the electrical conductivity of the nutrient solution (replaced every six days) using a portable pH/EC meter (HI 9813-6N, Hanna Instruments, Woonsocket, Rhode Island). The piped nutrient delivery system consisted of a reservoir with submersible pumps (model number AAPW400, Hydrofarm LLC, Pe- 
taluma, California) to facilitate nutrient delivery.

Reviewed reports have indicated that when grown in a soilless system, lettuce has a high yield and quality [26]. Pelleted Rex lettuce (Lactuca sativa) seeds (Johnny's selected seeds, Fairfield, Maine) were chosen for the crop for offered advantages such as lettuce include having a maximum height of thirty centimeters and having a growth cycle between ten to thirty days [27] [28]. As a preventative measure, we used bio-controls on our crops during the growth cycles in both growing locations.

\subsection{Experimental Procedure}

We wanted to study the performance of the growing locations over extreme weather over the year, and so we chose to run growing cycles over summer 2020 and winter 2020-2021. We ran the experiment for 44 days for each growing period in which the first fourteen days were the seedling stage until the lettuce plants were ready for transplant, followed by thirty days of crop production.

We sowed our pelleted Rex lettuce (Lactuca sativa) seeds to begin the seedling production stage and let it grow for two weeks until it was ready for transplant in OASIS ${ }^{\circledR}$ Horticubes (104 count, OASIS ${ }^{\circledR}$ Grower Solutions, Kent, Ohio) with dimensions of $2.54 \times 3.18 \times 3.81 \mathrm{~cm}$. After saturating it with plain tap water, we placed a single seed for every recess in the OASIS ${ }^{\circledR}$ Horticubes (placed on a black tray). We covered the placed seeds with a newspaper and put the covered tray with seeds in the dark inside the GREENBOX for 48 hours. After uncovering, we programmed GREENBOX lights to provide 16 hours of light per day. We irrigated the plants in the seedling stage using a starter fertilizer solution. We formulated the starter nutrient solution by mixing $3.6 \mathrm{~g}$ of "Jack's hydroponic 15.5-0-0" (calcium nitrate) and $3.8 \mathrm{~g}$ of "Jack's hydroponic 5-12-26" for every ten liters of water, which was half the strength of the regular strength solution used for crop production.

After fourteen days, the seedlings were ready for transplant when two true leaves (two leaves apart from the cotyledon) had expanded. Giving preference to healthier-looking transplants, we selected seedlings randomly from the OASIS ${ }^{\circledR}$ Horticubes to transplant into the NFT channels in the GREENBOX and greenhouse. We prepared the nutrient solution for irrigation, mixing $6 \mathrm{~g}$ of "Jack's hydroponic 15.5-0-0" (calcium nitrate) and $6.4 \mathrm{~g}$ of "Jack's hydroponic 5-12-26" for every ten liters of water. We circulated a nutrient solution in the NFT system with a target $\mathrm{pH}$ of 5.8 (maintained by adding acid or alkali, depending on the exceedance). We targeted EC of 1.5-2.0 mS (maintained by adding water or more fertilizer, depending on the exceedance).

\subsection{Data Acquisition}

Environmental variables including light intensity $\left(\mathrm{W} / \mathrm{m}^{2}\right)$, temperature $\left({ }^{\circ} \mathrm{C}\right)$, and relative humidity (\%) were collected using iPonic controllers that log data instantaneously every minute and are accessible via the cloud. The environmental 
data collected by the iPonic sensors had a precision of $0.1 \mathrm{~W} / \mathrm{m}^{2}$ for light, $0.1^{\circ} \mathrm{C}$ for temperature, and $1 \%$ for relative humidity. We harvested lettuce on the thirtieth day from the day of the transplant from the GREENBOX and greenhouse. We randomly selected two lettuce plants from both growing locations every three days for destructive sampling to obtain the wet and dry weights (g). To obtain the wet weight, we pulled apart the roots and any growing medium attached to the plant before weighing the lettuce immediately after harvest. The wet weight indicates the amount of biomass accumulated in the crop resulting from evapotranspiration. We blotted the plant gently with a soft paper towel to remove any free surface moisture and weighed the plants immediately after harvest. Finally, we obtained the lettuce's dry weight by drying the leaves (stored in a brown paper bag) in a forced air convection oven $\left(65^{\circ} \mathrm{C}\right.$ for six days). We derived the productivity of both growing locations using the wet weight values at harvest to determine the total biomass output in kilograms per square meter of growing area.

\subsection{Data Processing and Descriptive Statistics Analysis}

Lighting was represented by DLI $\left(\mathrm{mol} / \mathrm{m}^{2} \cdot \mathrm{d}\right)$ by using instantaneously measured light data $\left(\mathrm{W} / \mathrm{m}^{2}\right)$ and converted to cumulative light accumulated per day. Temperature and humidity were processed to 15 -minute averages using data from the iPonic environmental controllers. We used descriptive statistics to characterize the environmental data of DLI, temperature, and relative humidity, which were plotted to 15-minute averages over a thirty-day growing period for the summer and winter. We detailed their average values, along with their standard deviations except for light (provided values in the form of DLI). We report dry weight, wet weight, and productivity of lettuce crops in GREENBOX and greenhouse over summer and winter at harvest (Day 30).

\section{Results}

The descriptive statistics of the environmental variables are summarized in $\mathrm{Ta}$ ble 1, and the dynamic variations of these variables are shown in Figure 2 for both growing locations. The mean DLI in GREENBOX ranged between 32.48 $36.70 \mathrm{~mol} / \mathrm{m}^{2} \cdot \mathrm{d}$ over the two growing cycles (Table 2). It was purposely set higher than the recommended minimum DLI of $6.5-9.7 \mathrm{~mol} / \mathrm{m}^{2} \cdot \mathrm{d}$ [29]. The mean DLI in the greenhouse was significantly lower than GREENBOX, with average values of 14.52 and $10.44 \mathrm{~mol} / \mathrm{m}^{2} \cdot \mathrm{d}$ over summer and winter, respectively. Thus, the light conditions in the GREENBOX could be consistently regulated at the grower's discretion for optimal growth. Although the DLI in the GREENBOX showed a slight decline over each growing cycle due to the depreciation of light bulbs (Figure 2), the variations were so small that open field or greenhouse structures could not replicate due to changes in weather conditions and length of daytime over the year. The temperature regimes inside GREENBOXES were in the optimal range $\left(17^{\circ} \mathrm{C}-29^{\circ} \mathrm{C}[30]\right)$ to sustain lettuce growth over summer and 
Table 1. Light intensity (DLI), temperature $\left({ }^{\circ} \mathrm{C}\right)$, and relative humidity (\%) in GREENBOX (GB) and greenhouse (GH) over summer and winter.

\begin{tabular}{ccccccc}
\hline & \multicolumn{2}{c}{ DLI $\left(\mathrm{mol} / \mathrm{m}^{2} \cdot \mathrm{d}\right)$} & \multicolumn{2}{c}{ Temperature $\left({ }^{\circ} \mathrm{C}\right)$} & \multicolumn{2}{c}{ Humidity (\%) } \\
\hline Season & GB & GH & GB & GH & GB & GH \\
\hline Summer & $32.48^{1}$ & 14.52 & $26.99 \pm 0.93^{2}$ & $28.90 \pm 4.92$ & $58.54 \pm 4.77$ & $74.64 \pm 12.49$ \\
Winter & 36.70 & 10.44 & $24.50 \pm 1.09$ & $21.37 \pm 1.56$ & $35.53 \pm 6.27$ & $45.24 \pm 9.66$ \\
\hline
\end{tabular}

${ }^{1} \mathrm{DLI}$ are the mean values over growing season. ${ }^{2}$ Data shown for temperature and humidity are means with standard deviations (SD).
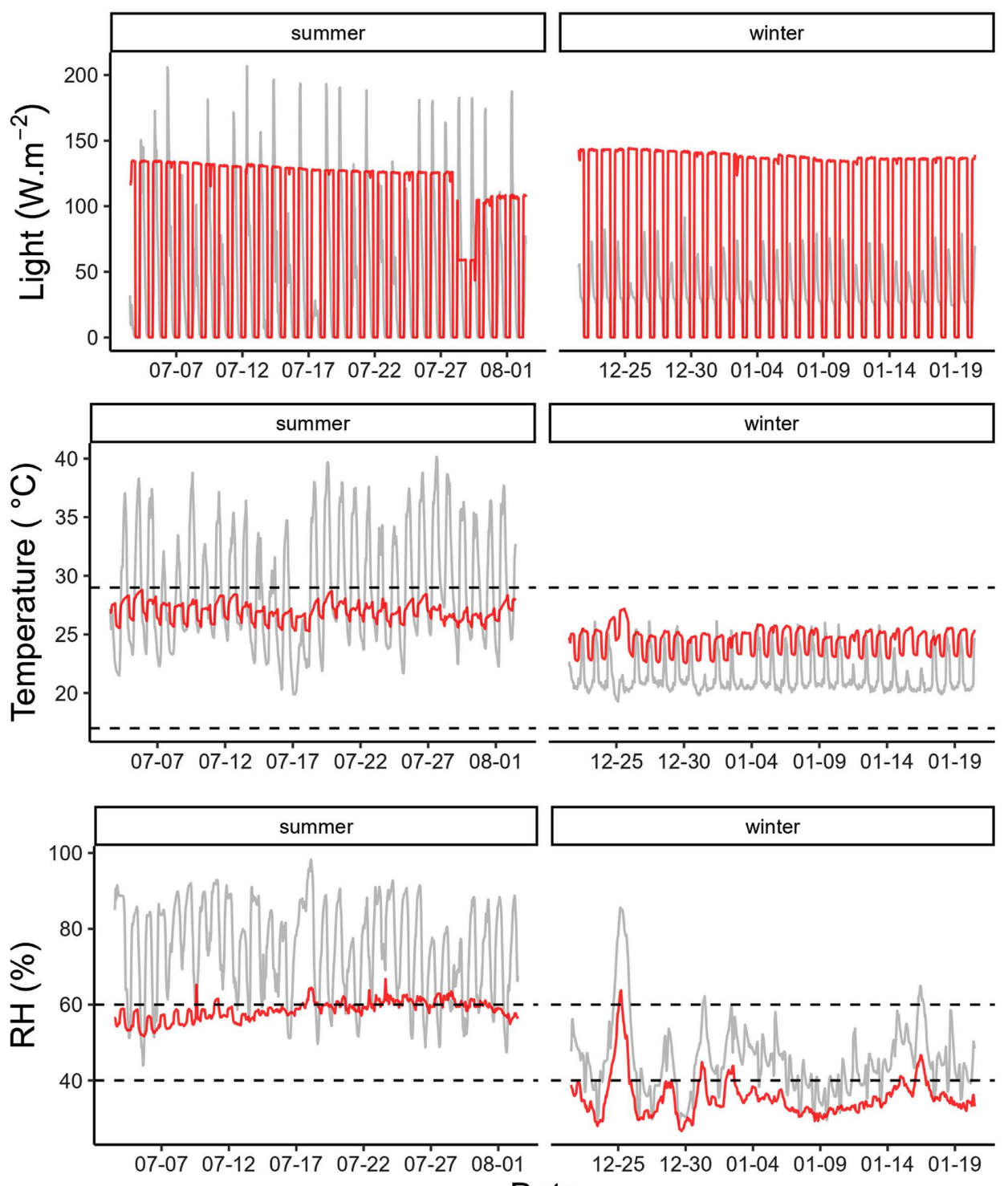

Date

Location - Greenhouse - GREENBOX

Figure 2. Light intensity (top, $\mathrm{W} / \mathrm{m}^{2}$ ), temperature (middle, ${ }^{\circ} \mathrm{C}$ ), and relative humidity (bottom, \%) in GREENBOX and greenhouse over summer (left) and winter (right). Data are 15-min averages. The dashed lines in the temperature and relative humidity charts indicate the optimal ranges for lettuce growth. 
Table 2. Dry weight, wet weight, and productivity in GREENBOX (GB) and greenhouse (GH) over summer and winter at harvest (Day 30 ).

\begin{tabular}{ccccccc}
\hline & $\begin{array}{c}\text { Dry weight at harvest } \\
(\mathrm{g})\end{array}$ & \multicolumn{2}{c}{$\begin{array}{c}\text { Wet weight at harvest } \\
(\mathrm{g})\end{array}$} & \multicolumn{2}{c}{$\begin{array}{r}\text { Average overall productivity } \\
\left(\mathrm{kg} / \mathrm{m}^{2}\right)\end{array}$} \\
\hline Season & GB & GH & GB & GH & GB & GH \\
\hline Summer & 8.72 & 11.80 & 231.58 & 229.57 & 7.38 & 7.02 \\
Winter & 6.5 & 6.53 & 187.35 & 188.3 & 6.33 & 6.01 \\
\hline
\end{tabular}

winter without significant variation over the day (average temperatures of $26.99^{\circ} \mathrm{C} \pm 0.93^{\circ} \mathrm{C}$ and $24.50^{\circ} \mathrm{C} \pm 1.09^{\circ} \mathrm{C}$ over summer and winter, respectively). However, the greenhouse temperatures exceeded the optimal temperatures with a significantly higher variation, especially during summer (average temperatures of $28.90^{\circ} \mathrm{C} \pm 4.92^{\circ} \mathrm{C}$ and $21.37^{\circ} \mathrm{C} \pm 1.56^{\circ} \mathrm{C}$ over summer and winter, respectively). The main heating source in the GREENBOX is the lighting element. Due to the insulation from external weather fluctuations provided by the warehouse and the thermally insulated walls of GREENBOX structure, the seasonal and diurnal temperature variations were minimal over the year compared to the greenhouse (Figure 2). The GREENBOX structures also sustained ambient humidity conditions between $40 \%$ - 60\% (desirable range for most crops, including lettuce) for most of the time, higher in summer and lower in winter. In any case, the relative humidity was below $70 \%$ and thus did not affect crop growth. The average relative humidity was lower over summer $(58.54 \% \pm 4.77 \%)$ and winter $(35.53 \% \pm$ $6.27 \%)$ in GREENBOX, and higher in greenhouse in the summer $(74.64 \% \pm$ $12.49 \%)$ and winter $(45.24 \% \pm 9.66 \%)$, with a much higher variation over the day in the greenhouse (demonstrated by higher standard deviation values in Table 1). The fluctuations are significantly higher and immediate to weather events such as cloud cover and precipitation as the greenhouse is directly exposed to external elements. Overall, the lettuce crops' environmental conditions over the summer and winter indicated that GREENBOX technology could provide the desired environment to sustain growth year-round, with lower fluctuations and higher consistency (compared to greenhouse).

The biomass and productivity data collected at harvest found that measured variables were similar across growing locations, with slightly higher values over summer than winter, as presented in Table 2. The dry weight at harvest was higher in the greenhouse ( $11.80 \mathrm{~g}$ in summer and $6.53 \mathrm{~g}$ in winter, respectively) than GREENBOX (8.72 $\mathrm{g}$ in summer and $6.5 \mathrm{~g}$ in winter, respectively). We found the wet weight is consistently higher in summer (231.58 $\mathrm{g}$ in GREENBOX and $229.57 \mathrm{~g}$ in greenhouse, respectively) than in winter (187.35 $\mathrm{g}$ in GREENBOX and $188.3 \mathrm{~g}$ in greenhouse, respectively). Wet weight and dry weight represent the cumulative amount of gas exchange in photosynthesis and evapotranspiration over the growing cycle [31]. The productivity across growing locations was not significantly different in the same season but was higher over the summer 
(7.38 $\mathrm{kg} / \mathrm{m}^{2}$ in GREENBOX and $7.02 \mathrm{~kg} / \mathrm{m}^{2}$ in greenhouse) than in winter (6.33 $\mathrm{kg} / \mathrm{m}^{2}$ in GREENBOX and $6.01 \mathrm{~kg} / \mathrm{m}^{2}$ in greenhouse, respectively). There were subtle differences among seasons, but such differences did not cause a significant difference in crop growth and productivity over growing locations.

\section{Discussion}

The results indicate that the GREENBOX provided the required environmental conditions to sustain lettuce crop growth from seedling to full bloom and ready for consumption. The growth in the GREENBOX followed similar patterns to greenhouse crop production (grown for reference). Furthermore, the environmental conditions provided in both growing locations were within the optimal range for crop sustenance. Environmental parameters were more consistent and controllable in the GREENBOX. The temperature variations over summer were almost five times higher in the greenhouse $\left( \pm 4.92^{\circ} \mathrm{C}\right)$ than GREENBOX $\left( \pm 0.93^{\circ} \mathrm{C}\right)$. However, the variations over winter were not that drastically variable over both growing locations $\left( \pm 1.09^{\circ} \mathrm{C}\right.$ in GREENBOX and $\pm 1.56^{\circ} \mathrm{C}$ in greenhouse, respectively). We attribute the higher variability in the greenhouse over summer due to the lower capability of the greenhouse climate control in response to the high variation in solar energy. Summer has the longest duration of light over the year, and despite using shade curtains to control the intensity of sun rays hitting the crops, the trapped infrared rays led to higher temperatures in the greenhouse (due to the greenhouse effect). Care must be taken to maintain relative humidity at an optimum level, as high relative humidity can lead to fungal disease, and if relative humidity is too low it can cause stunted growth [32]. The GREENBOX and greenhouse provided these conditions comfortably during growth over the summer and winter. As expected, the humidity over winter in both growing locations was lower than in summer. Variations in relative humidity over winter were significantly higher in the greenhouse $( \pm 12.49 \%)$ than GREENBOX $( \pm 4.77 \%)$. The variation over winter was higher in the greenhouse $( \pm 9.66 \%)$ than GREENBOX $( \pm 6.27 \%)$. The relative humidity trends in the greenhouse were directly affected by external weather, sometimes rising to almost $96 \%$ during a rainstorm and decreasing to lower values when there is no rain for an extended time. By virtue of the GREENBOX having an independent lighting source, crop production is not dependent on sunlight and variation on cloud covers and weather events.

There are advantages to growing crops in a controlled environment. The GREENBOX is not as drastically affected by the external weather due to the sole reliance on an artificial lighting source for its photosynthetic needs. GREENBOX can potentially multiply its production capacity by vertical stacking. Lettuce crop production times vary year-round due to differences in daylight (sunlight) length over the year. However, year-round lettuce production is possible by maintaining a consistent DLI [33], lighting intensity, and time length. Controlled environment agriculture can achieve uniform crop and extension of 
growing seasons by controlling environmental and cultural factors [34]. Future GREENBOX trials include a heater/air conditioners combination to precisely modulate temperature levels and a combination of humidifier/dehumidifier to control moisture levels at optimal levels.

While the productivity was similar in the GREENBOX and greenhouse, there was a noticeable difference in productivity (almost one $\mathrm{kg} / \mathrm{m}^{2}$ ) and wet weight (around $40 \mathrm{~g}$ ) at harvest between the summer and winter. We attribute this phenomenon to a higher evapotranspiration rate and subsequent growth due to higher temperatures. The GREENBOX primary heating source was the lighting element; future iterations may include a heat pump to supplement heat sources to combat colder conditions.

In response to the growing awareness of the carbon footprint associated with increased food miles, a growing social movement has been to eat locally sourced food (known as locavores) [35]. As a result, there is a growing consumer base of locavores willing to pay a premium for locally grown produce that is hyper-fresh [36]. The total supply chain of food needs 4200 miles (6760 kilometers) of movement, and 1020 miles (1640 kilometers) is the final average food miles traveled in the United States [4]. Therefore, a decrease in food miles traveled can be linked to a lower carbon footprint and alleviate the effects of climate change [37]. When placed in strategic areas, GREENBOX can potentially reduce the food miles problem by making fresh produce more accessible. Scaling up localized high yield controlled environment agricultural setups (such as greenhouses, indoor vertical farms, or plant factories) can help increase the resilience of the food supply systems [38]. With GREENBOX technology, one can design plant factory setups closer to the point of consumption (restaurant and stores) such that the produce can be quickly harvested and sold, saving resources on preservation and transportation, along with space saved for inventory [39].

There is promising potential for the GREENBOX in leafy green crop production in urban areas. Consumption growth and increasing populations will mean that global food demand will comfortably exist for forty years at a minimum [40]. Over twenty years, a five-fold increase in sales has been noted for salad-mixes in the United States [41]. As of 2018, worldwide controlled environment agriculture was valued at 26.8 billion USD [42], with a projected $9.19 \%$ growth between 2020-2025 [43]. Leafy vegetables such as lettuce are also gaining popularity as they represent practical and convenient foods with high nutritional content [44]. Clinical investigations have demonstrated a direct inverse link between a lower incidence of chronic disease (e.g., neurodegenerative and cardiovascular disease) and high consumption of green leafy vegetables, owing to it being a good source of antioxidants, phytochemicals, vitamins, and minerals [45]. GREENBOX can potentially serve as an excellent resource for educational purposes. Students from various disciplines such as engineering, life sciences, and technology can learn of all ages [46].

Urban areas can easily meet the resources requirements for a viable urban 
agricultural setup, such as light, heat, carbon dioxide, water, space, and airflow. GREENBOX may use water from the city water supply but can use greywater or stormwater streams in cities. There are many potential avenues in urban areas that GREENBOX can be used such as underground unused tunnels and basements, flat, unused rooftops, vacant spaces in occupied buildings such as atriums, open planned spaces and corridors, and abandoned vacant spaces within buildings (empty, unoccupied floors). There is great potential for incorporating CEA setups in urban areas as more than $60 \%$ of construction is pending to match the projected urban area to be developed by 2030 [5]. There are new commercial establishments in this field, such as Gotham Greens claims that their crop production is 30 times more compared to traditional methods with locations in New York and Chicago and are rapidly expanding across the United States [46].

There are many goals future iterations of GREENBOX can aim for as a CEA setup. An ideal CEA setup must strive for a decrease in variation in environmental parameters [47]. An ideal CEA setup should be designed to be upgraded with the least cost and minimum modification and maintenance. An ideal CEA setup should strive for the right balance between automation (transportation, packaging, management, and cleaning), labor-saving measures, and job security [48]. CEA setups have the advantage of a small physical footprint [49]. We may also include different types of crop growth such as spinach, pakchoi, kale, swiss chard, among many others. We may also use fruiting plants such as cherry tomatoes, strawberries, among many others. Our current study used warehouse conditions for GREENBOX crop production; we can also use other areas such as abandoned mills, strip malls, or shipping containers. The current project was a pilot study as a proof of concept, and therefore we used commercially available materials to assemble the GREENBOX. Future trials may include materials that use low-cost thermally insulated prototypes and are explicitly designed for this purpose.

\section{Conclusion}

This study demonstrated our novel GREENBOX technology as an alternative and sustainable avenue for vegetable crop production in urban settings. We presented our observations on the environmental parameters and biomass output of two GREENBOX units. Preliminary comparisons were made with a simultaneous growing cycle in an experimental greenhouse. The study found that the GREENBOX provided the required environmental conditions to sustain lettuce crop growth to full bloom and demonstrated that these structures could sustain growth in mid-latitude climates. The environmental conditions in the GREENBOX structure were largely within the optimal range with minimal fluctuations. The DLI ranged between $32.48-36.70 \mathrm{~mol} / \mathrm{m}^{2} \cdot \mathrm{d}$ at crop canopy height as set by the grower. The mean daily temperature fell within the optimum range of $17^{\circ} \mathrm{C}$ $29^{\circ} \mathrm{C}$, and relative humidity was also in the ideal range of $40 \%-60 \%$ for lettuce 
crop production. The growing environment in the GREENBOX was highly controllable and could be regulated at the growers' discretion. The lettuce crops grew to healthy full size (ready for consumption) with similar productivity between both growing facilities. Based on the results of our study, we would conclude that the GREENBOX technology may have a high applicability and potential in urban food production, due to its low (almost zero) requirement for arable land and its ability to produce fresh food for local concentrated population.

\section{Acknowledgements}

The study was partially supported by a Hatch project (Project No. CONS01000) from USDA NIFA. We are also grateful to the Raudales Laboratory at the University of Connecticut for providing supporting materials and training, and to the greenhouse staff (Frederick Petit and Shelly Durocher) for providing critical support for carrying out the experiments over the year. We also want to express our gratitude to the Statistical Consulting Services (Dr. Timothy E. Moore) at the University of Connecticut for providing support for statistical help for this project.

\section{Conflicts of Interest}

The authors declare no conflicts of interest regarding the publication of this paper.

\section{References}

[1] Kloas, W., Groß, R., Baganz, D., Graupner, J., Monsees, H., Schmidt, U., Staaks, G., Suhl, J., Tschirner, M., Wittstock, B., Wuertz, S., Zikova, A. and Rennert, B. (2015) A New Concept for Aquaponic Systems to Improve Sustainability, Increase Productivity, and Reduce Environmental Impacts. Aquaculture Environment Interactions, 7, 179-192. https://doi.org/10.3354/aei00146

[2] Pison, G. (2017) Tous les pays du monde. Population \& Sociétés, No. 547, 1-8. https://doi.org/10.3917/popsoc.547.0001

[3] Conforti, P., Alexandratos, N., Anriquez, G., Baffes, J., Beintema, N., Boedeker, G. and Bruinsma, J. (2011) World Food and Agriculture to 2030/2050 Revisited. Highlights and Views Four Years Later. In: Conforti, P., Ed., Looking Ahead in World Food and Agriculture: Perspectives to 2050, Food and Agriculture Organization of the United Nations, Rome, 11-56. http://www.fao.org/docrep/014/i2280e/i2280e.pdf

[4] Specht, K., Siebert, R., Hartmann, I., Freisinger, U.B., Sawicka, M., Werner, A., Thomaier, S., Henckel, D., Walk, H. and Dierich, A. (2014) Urban Agriculture of the Future: An Overview of Sustainability Aspects of Food Production in and on Buildings. Agriculture and Human Values, 31, 33-51. https://doi.org/10.1007/s10460-013-9448-4

[5] Kozai, T., Next, T., Indoor, G. and Farms, V. (2018) Smart Plant Factory. Springer, Singapore. https://doi.org/10.1007/978-981-13-1065-2

[6] Ortiz-Bobea, A., Ault, T.R., Carrillo, C.M., Chambers, R.G. and Lobell, D.B. (2021) Anthropogenic Climate Change Has Slowed Global Agricultural Productivity Growth. Nature Climate Change, 11, 306-312. https://doi.org/10.1038/s41558-021-01000-1 
[7] Taghizadeh, R. (2021) Assessing the Potential of Hydroponic Farming to Reduce Food Imports: The Case of Lettuce Production in Sweden. Master's Thesis, Uppsala universitet, Uppsala.

[8] Cummins, S., Flint, E. and Matthews, S.A. (2014) New Neighborhood Grocery Store Increased Awareness of Food Access but Did Not Alter Dietary Habits or Obesity. Health Affairs, 33, 283-291. https://doi.org/10.1377/hlthaff.2013.0512

[9] Hendrickson, D., Smith, C. and Eikenberry, N. (2006) Fruit and Vegetable Access in Four Low-Income Food Deserts Communities in Minnesota. Agriculture and $\mathrm{Hu}$ man Values, 23, 371-383. https://doi.org/10.1007/s10460-006-9002-8

[10] Cubbin, C., Hadden, W.C. and Winkleby, M.A. (2001) Neighborhood Context and Cardiovascular Disease Risk Factors: The Contribution of Material Deprivation. Ethnicity \& Disease, 11, 687-700. http://europepmc.org/abstract/MED/11763293

[11] Deaton, A. and Lubotsky, D. (2003) Mortality, Inequality and Race in American Cities and States. Social Science and Medicine, 56, 1139-1153. https://doi.org/10.1016/S0277-9536(02)00115-6

[12] Yang, W., Dall, T.M., Beronjia, K., Lin, J., Semilla, A.P., Chakrabarti, R., Hogan, P.F. and Petersen, M.P. (2018) Economic Costs of Diabetes in the U.S. in 2017. Diabetes Care, 41, 917-928. https://doi.org/10.2337/dci18-0007

[13] Hammond, R. and Levine. (2010) The Economic Impact of Obesity in the United States. Diabetes, Metabolic Syndrome and Obesity. Targets and Therapy, 3, 285-295. https://doi.org/10.2147/DMSOTT.S7384

[14] Oldani, C. (2020) The Multiple Benefits of Urban Agriculture: Contexts and Contributions of a Modern Food Movement. Vanderbi Lt Undergraduate Research Journal, 11, 86-102. https://doi.org/10.15695/vurj.v11i1.5059

[15] Zhang, X., He, D., Niu, G., Yan, Z. and Song, J. (2018) Effects of Environment Lighting on the Growth, Photosynthesis, and Quality of Hydroponic Lettuce in a Plant Factory. International Journal of Agricultural and Biological Engineering, 11, 33-40. https://doi.org/10.25165/j.ijabe.20181102.3240

[16] Kozai, T. (2019) Towards Sustainable Plant Factories with Artificial Lighting (PFALs) for Achieving SDGs. International Journal of Agricultural and Biological Engineering, 12, 28-37. https://doi.org/10.25165/j.ijabe.20191205.5177

[17] Goodman, W. and Minner, J. (2019) Will the Urban Agricultural Revolution Be Vertical and Soilless? A Case Study of Controlled Environment Agriculture in New York City. Land Use Policy, 83, 160-173. https://doi.org/10.1016/j.landusepol.2018.12.038

[18] Thomaier, S., Specht, K., Henckel, D., Dierich, A., Siebert, R., Freisinger, U.B. and Sawicka, M. (2015) Farming in and on Urban Buildings: Present Practice and Specific Novelties of Zero-Acreage Farming (Z Farming). Renewable Agriculture and Food Systems, 30, 43-54. https://doi.org/10.1017/S1742170514000143

[19] Orsini, F., Pennisi, G., Zulfiqar, F. and Gianquinto, G. (2020) Sustainable Use of Resources in Plant Factories with Artificial Lighting (PFALs). European Journal of Horticultural Science, 85, 297-309. https://doi.org/10.17660/eJHS.2020/85.5.1

[20] Aciksoz, S., Dal, I. and Özbek, M.Ö. (2021) Smart Urban Agriculture. In: Developments in Engineering and Architecture, St. Kliment Ohridski University Press, Sofia, 102-114.

[21] Vitoshkin, H., Grinshpun, J. and Haslavsky, V. (2021) Experimental Modeling and Thermal Analysis of Closed Hydroponic System Microclimate. Journal of Fluid Flow, Heat and Mass Transfer, 8, 1-5. https://doi.org/10.11159/jffhmt.2021.001 
[22] Yang, X., Theobald, D., McAvoy, R., Wu, J. and Liu, C. (2017) Greenbox Farming: A New System for Urban Agriculture. 2017 ASABE Annual International Meeting, Spokane 16-19 July 2017, Article ID: 1700627. https://doi.org/10.13031/aim.201700627

[23] Wu, J., Yang, X., Mcavoy, R., Raudales, R., Theobald, D., Liu, C. and Author, C. (2018) Energy and Water Use Analysis for the Greenbox System in Comparison with the Traditional Greenhouse. 2018 ASABE International Meeting, Detroit, July 29-1 August 2018, 1-17.

[24] Runkle, J., Kunkel, K., Champion, S., Easterling, D., Stewart, B., Frankson, R. and Sweet, W. (2017) Connecticut State Climate Summary. NOAA Technical Report NESDIS, 149-CT, National Oceanic and Atmospheric Administration, Washington DC, $4 \mathrm{p}$.

[25] Jensen, M.H. (2002) Controlled Environment Agriculture in Deserts, Tropics and Temperate Regions-A World Review. Acta Horticulturae, 578, 19-25. https://doi.org/10.17660/ActaHortic.2002.578.1

[26] Ahmed, Z.F.R., Alnuaimi, A.K.H., Askri, A. and Tzortzakis, N. (2021) Evaluation of Lettuce (Lactuca sativa L.) Production under Hydroponic System: Nutrient Solution Derived from Fish Waste vs. Inorganic Nutrient Solution. Horticulturae, 7, Article No. 292. https://doi.org/10.3390/horticulturae7090292

[27] Kozai, T., Niu, G. and Takagaki, M. (2015) Plant Factory: An Indoor Vertical Farming System for Efficient Quality Food Production. Academic Press, Cambridge. https://books.google.com/books?id=z-C7DwAAQBAI

[28] Liu, H., Fu, Y., Wang, M. and Liu, H. (2017) Green Light Enhances Growth, Photosynthetic Pigments and $\mathrm{CO}_{2}$ Assimilation Efficiency of Lettuce as Revealed by 'Knock Out' of the 480 - $560 \mathrm{~nm}$ Spectral Waveband. Photosynthetica, 55, 144-152. https://doi.org/10.1007/s11099-016-0233-7

[29] Paz, M., Fisher, P.R. and Gómez, C. (2019) Minimum Light Requirements for Indoor Gardening of Lettuce. Urban Agriculture \& Regional Food Systems, 4, 1-10. https://doi.org/10.2134/urbanag2019.03.0001

[30] Holmes, S.C., Wells, D.E., Pickens, J.M. and Kemble, J.M. (2019) Selection of Heat Tolerant Lettuce (Lactuca sativa L.) Cultivars Grown in Deep Water Culture and Their Marketability. Horticulturae, 5, Article No. 50. https://doi.org/10.3390/horticulturae5030050

[31] Menke, K.H. and Steingass, H. (2016) Chapter 10. Growth, Development, Transpiration and Translocation as Affected by Abiotic Environmental Factors. In: Kozai, T., Niu, G. and Takagaki, M., Eds., Plant Factory, Academic Press, Cambridge, 151-164. https://doi.org/10.1016/B978-0-12-801775-3.00010-X http://www.ncbi.nlm.nih.gov/pubmed/8822346

[32] Ryu, D.K., Kang, S.W., Ngo, V.D., Chung, S.O., Choi, J.M., Park, S.U. and Kim, S.J. (2014) Control of Temperature, Humidity, and $\mathrm{CO}_{2}$ Concentration in Small-Sized Experimental Plant Factory. Acta Horticulturae, 2, 477-484. https://doi.org/10.17660/ActaHortic.2014.1037.59

[33] Albright, L.D., Both, A.J. and Chiu, A.J. (2000) Controlling Greenhouse Light to a Consistent Daily Integral. Transactions of the American Society of Agricultural Engineers, 43, 421-431. https://doi.org/10.13031/2013.2721

[34] Vaštakaitè-Kairienè, V., Kelly, N. and Runkle, E.S. (2021) Regulation of the Photon Spectrum on Growth and Nutritional Attributes of Baby-Leaf Lettuce at Harvest and during Postharvest Storage. Plants, 10, Article No. 549. 
https://doi.org/10.3390/plants10030549

[35] Peterson, H.H., Taylor, M.R. and Baudouin, Q. (2015) Preferences of Locavores Favoring Community Supported Agriculture in the United States and France. Ecological Economics, 119, 64-73. https://doi.org/10.1016/j.ecolecon.2015.07.013

[36] Eaves, J. and Eaves, S. (2018) Comparing the Profitability of a Greenhouse to a Vertical Farm in Quebec. Canadian Journal of Agricultural Economics, 66, 43-54. https://doi.org/10.1111/cjag.12161

[37] Coley, D., Howard, M. and Winter, M. (2009) Local Food, Food Miles and Carbon Emissions: A Comparison of Farm Shop and Mass Distribution Approaches. Food Policy, 34, 150-155. https://doi.org/10.1016/j.foodpol.2008.11.001

[38] Weidner, T., Yang, A. and Hamm, M.W. (2021) Energy Optimisation of Plant Factories and Greenhouses for Different Climatic Conditions. Energy Conversion and Management, 243, Article ID: 114336.

https://doi.org/10.1016/j.enconman.2021.114336

[39] Jassem, S. and Rezaur Razzak, M. (2020) Entrepreneurship in Urban Jungles through High-Tech Vertical Farming. In: Turuk, M., Ed., Entrepreneurship, IntechOpen, London, 13. https://doi.org/10.5772/intechopen.93667

[40] Prosekov, A.Y. and Ivanova, S.A. (2018) Food Security: The Challenge of the Present. Geoforum, 91, 73-77. https://doi.org/10.1016/j.geoforum.2018.02.030

[41] Grahn, C.M., Benedict, C., Thornton, T. and Miles, C. (2015) Production of Baby-Leaf Salad Greens in the Spring and Fall Seasons of Northwest Washington. HortScience, 50, 1467-1471. https://doi.org/10.21273/HORTSCI.50.10.1467

[42] Engler, N. and Krarti, M. (2021) Review of Energy Efficiency in Controlled Environment Agriculture. Renewable and Sustainable Energy Reviews, 141, Article ID: 110786. https://doi.org/10.1016/j.rser.2021.110786

[43] Research, G.V. (2018) Indoor Farming Market Size, Share \& Trends Report Indoor Farming Market Size, Share \& Trends Analysis Report by Facility Type (Greenhouses, Vertical Farms), by Component (Hardware, Software), by Crop Category, by Region, and Segment Forecasts, 2019-2025.

https://www.grandviewresearch.com/industry-analysis/indoor-farming-market

[44] Chen, Z., Jahan, M.S., Mao, P. and Wang, M. (2020) Functional Growth, Photosynthesis and Nutritional Property Analyses of Lettuce Grown under Different Temperature and Light Intensity. The Journal of Horticultural Science and Biotechnology, 96, 53-61. https://doi.org/10.1080/14620316.2020.1807416

[45] Colonna, E., Rouphael, Y., Barbieri, G. and De Pascale, S. (2016) Nutritional Quality of Ten Leafy Vegetables Harvested at Two Light Intensities. Food Chemistry, 199, 702-710. https://doi.org/10.1016/j.foodchem.2015.12.068

[46] La Plante, G., Andrekovic, S., Young, R.G., Kelly, J.M., Bennett, N., Currie, E.J. and Hanner, R.H. (2021) Canadian Greenhouse Operations and Their Potential to Enhance Domestic Food Security. Agronomy, 11, Article No. 1229. https://doi.org/10.3390/agronomy11061229

[47] Lee, C.-Y., Huang, Y.-K., Lin, T.-S., Shieh, J.-C., Chou, J.-J., Lee, C.-Y., Jiang, J.-A. and Smart, A. (2013) A Smart Fan System for Temperature Control in Plant Factory.

[48] Park, J.E. and Nakamura, K. (2015) Automatization, Labor-Saving and Employment in a Plant Factory. Environmental Control in Biology, 53, 89-92.

https://doi.org/10.2525/ecb.53.89 
[49] Harbick, K. and Albright, L.D. (2016) Comparison of Energy Consumption: Greenhouses and Plant Factories. Acta Horticulturae, 1134, 285-292.

https://doi.org/10.17660/ActaHortic.2016.1134.38 